\section{Neurological Outcome of Stenting in Carotid Occlusive Diseases}

ORIGINAL

\section{Abstract}

Background: Carotid artery stenting (CAS) has become widely available and considered as an alternative to carotid endartectomy.

Objective: To compare CAS under protection device with medical treatment.

Material and Method: Fifty patients were enrolled in these study (30 patients treated with carotid stenting and 20 patients man-aged medically) with stenosis $>60 \%$ with follow up at six months later clinically and radiologically using carotid duplex.

Result: After 6 months 4 (13.4\%) patients in CAS group develop TIA while in medically treated group $6(30 \%)$ patients, 1 (3.3\%) patient in CAS group develop stroke which was after procedure while 6 (30\%) patients in medically treated group develop stroke during follow up within 6 months, 1 (3.3\%) patient die in CAS group due to myocardial infarction, while in medically treated group $2(10 \%)$ patients died one of them due to large stroke and the other due to myocardial infarction. There was high significant difference between CAS and medical treated group after 6 months $(p<0.01)$.

Conclusion: CAS under protection device is associated with better outcome than medical treatment.

\section{Introduction}

Stroke is estimated to be responsible for 5.5 million deaths worldwide annually. It is now the leading cause of disability in developed countries. Of those affected by first stroke approximately one third die, one third recover and one third are disabled [1].
Mohamed Abdel Salam", Hossam Egila1, Hassan Salama', Mohamed Shehab-Eldin ${ }^{1}$

1 Department of Neurology, Mansoura University, Mansoura, Egypt.

Contact information:

Hossam Egila.

”d drhosamegila@gmail.com

Keywords

Carotid Artery Stenting; Medical Treatment; Neurological Outcome; Carotid Stenosis. 
Stroke risk increase with stenosis severity and plaque morphology. The aim of the treatment of carotid artery stenosis is to prevent neurological complications; this could be achieved by medical treatment, surgical or endovascular interventions [2].

Complications related to CEA which either early or late and Some them are devastating complications that involve the neurological system. These tend to occur early, within the first 30 days after surgery. [3].

Since the inception of carotid angioplasty over two decades ago, techniques and equipment for carotid artery stenting (CAS) have radically improved. Equipment with lower profile (e.g., smaller outer diameter sheaths with large inner lumen, 0.014" system balloon catheters and stent catheters) and targeted to carotid arteries (e.g., emboli protection devices, self-expanding stents) have evolved dramatically, lead-ing to improved technical success and procedural safety of CAS especially for high risk surgical patients with low morbidity and mortality. [4].

\section{Materials and Methods}

This prospective study was conducted on fifty patients with carotid stenosis more than $60 \%$ between 2011 and 2015 after obtaining a written informed consent from all patients. Thirty patient treated with carotid stenting and twenty patients were managed medically. Exclusion criteria include Major func-tional impairment (modified Rankin Scale $\geq 3$ ), Significant cognitive impairment. Major stroke within 4 weeks (new neurological event that persisted after 7 days and increased NIH stroke scale score by $\geq 4$. Contraindication to acetylsalicylic or dual antiplatelet treatment for 4 weeks. Inability to achieve safe vascular access, Intracranial aneurysm > $2 \mathrm{~mm}$ or AVM requiring treatment. Concentric heavy lesion calci-fication, visible thrombus in lesion. Total occlusion and Long subtotal occlusion (string sign).

All patients were subjected to complete history taking,bed side examination including general ex- aminations, full neurological examinations scales (NIHSS) scale [5] and modified Rankin Scale [6] at 4 points (Before CAS, within 3 days after the procedure, one month, 6 months after the procedure, and when necessary).

Also carotid duplex \pm MRA or CTA (neck vessels) at day zero and after 6 months and laboratory investi-gations (complete blood count, PT, PTT, liver and renal function tests, random blood sugar, lipid profile and serum uric acid), ECG and trans-thoracic echocardiography.

\section{CAS Procedure}

All patients will be treated with acetyl-salicylic acid (150 mg/d) associated with clopidogrel $(75 \mathrm{mg} / \mathrm{d}$ ) for one week or $300 \mathrm{mg}$ clopidogrel at least 24 $\mathrm{h}$ before the procedure. the procedures were performed with local anesthesia then percutaneous transfemoral access F8 with heparin to achieve an activated clotting time (ACT) longer than 200-250 sec. and atropine $(0.51 \mathrm{mg}$ IV) will be given in order to reduce the bradycardia and hypotension potentially associated with carotid dilation.

All patients will undergo an angiographic examination of the culprit carotid lesion in at least two different real-time projections and an angiographic examination of intracranial circulation in anteroposterior and lateral projection.

The guidewire will be used to cross the carotidartery stenosis first, and then the filter will be expanded before the stent deployment.

Carotid stenting will be carried out by using selfexpandable crush resistant stents (Smart PreciseCordis or Carotid Wallstent -Boston Scientific).

The pre-dilation balloons will be routinely undersized (artery: balloon ratio $=2: 1.5$ ) in order to reduce vessel dissection and/or distal embolization.

Stent placement will be optimized through single or multiple postdilatations by using suitably sized balloons based on angiographic quantitative analysis of the vessel. 
Procedural success was defined as; to achieve a less than $30 \%$ residual diameter stenosis of the treated lesion in at least two matched views on angiography and finally absence of distal embolization.

Medical treated group took double antiplatelet (DAP) group (acetyl-salicylic acid 150 mg/day + clopidogrel $75 \mathrm{mg} /$ day), statins, controlling the associated modifiable atherogenic risk factors and were followed for at least 6 months clinically using NIHSS and MRS and radiological using carotid duplex \pm MRA or CTA.

\section{Statistical Analysis}

Data was analyzed on an IBM personal computer, using Statistical Package for Special Science (SPSS) software computer program version 15 . Then data described as mean \pm standard deviation (SD) for quan-titative (Numerical) variables and as frequency and percentage for qualitative (Categorical) variables. Chi-square test (or Fisher's exact test when appropriate) used for comparison of distribution of qualitative variables among different group.

\section{Results}

The study was conducted on 50 patients with mean age \pm standard deviation (66 \pm 7.92$) .17$ (56.6\%) patients in CAS group were male patients while 13 (43.4\%) patients were female. In medically treated group 10 (50\%) patients were male and 10 (50\%) patients were female with no statically difference between male and female ( $p>0.05)$.In CAS group $8(26.8 \%)$ patients had Moderate stenosis (50\%$69 \%$ stenosis), 20 (66.6\%) patients had sever stenosis (70\%-95\% stenosis) and 2 (6.6\%) patients had critical stenosis (96\%-99\% stenosis), while in medically treated group, 7 (35\%) patients had moderate stenosis, 11 (55\%) patients had sever stenosis and $2(10 \%)$ patients had critical stenosis with no statically difference between CAS and Medically treated group ( $p>0.05)$.
Main risk factors include diabetes mellitus that was detected in 21 (70\%) patients in CAS and in 14 (70\%) patients in medically treated group, hypertension detected in 19 (63.3) patients in CAS and in12 (60\%) patients in medically treated group.

$17(56.6 \%)$ patients in CAS group had Coronary artery disease (CAD) while 11 (55\%) patients in medically treated group had CAD. AF was detected in $9(30 \%)$ patients in CAS group and in $6(30 \%)$ patients in medically treated group. Dyslipedimia was detected in 22 (73.3\%) patients in CAS group and in 14 (70\%) patients in medically treated group. 13 (43.3\%) patients in CAS group were smokers while 8 (40\%) patients in medically treated group. Peripheral vascular disease were detected in 4 (13.3\%) patients in CAS group and in $4(20 \%)$ patients in medically treated group. History of Previous stroke in 5 (16.6\%) patients in CAS group and in 3 (15\%) patients bin medically treated group. With no statically difference between CAS and medically treated group ( $p>0.05$ ). According to disability as regard MRS at presentation in each group, 8 (26.6\%) patients in CAS had MRS 0.22 (73.4) patients had MRS 1-2 and no patients had MRS 3, while in medically treated group 4 (20\%) patients had MRS 0, 16 (80\%) patients had MRS 1-2 and no patients had MRS 3,with no statically difference between CAS and Medically treated group ( $p>0.05)$. As regard NIHSS at presentation, 8 (26.7\%) patients in CAS group were normal (NIHSS was 0),7 (23.3\%) patients had mild stroke (NIHSS 1-5),15 (50\%) patients had moderate stroke (NIHSS 6-15) and no patient had moderate to sever (NIHSS 16-25) or sever stroke (NIHSS 26-42), while in medically treated group 4 (20\%) patients were normal, 7 (35\%) patients had mild stroke, 9 (45\%) patients had moderate stroke and no patient had moderate to sever or sever stroke. With no statically difference between CAS and medically treated group ( $p>0.05$ ).

(Table 1, 2 \& 3) 
Table 1. Age ,sex and degree of stenosis distribution in CAS and medically treated groups.

\begin{tabular}{|c|c|c|c|}
\hline \multirow{2}{*}{\multicolumn{2}{|c|}{ Medically Treated Groups }} & \multirow[t]{2}{*}{ CAS } & \multirow[t]{2}{*}{$\begin{array}{l}\text { Medical } \\
\text { treatment }\end{array}$} \\
\hline & & & \\
\hline \multicolumn{2}{|c|}{ Age mean $\pm S D$} & \multicolumn{2}{|c|}{$66.24 \pm 7.92$} \\
\hline \multirow{2}{*}{ Sex } & Male number (\%) & $17(56.6 \%)$ & $10(50 \%)$ \\
\hline & Female number (\%) & $13(43.4 \%)$ & $10(50 \%)$ \\
\hline \multicolumn{2}{|c|}{ Total } & 30 & 20 \\
\hline \multicolumn{4}{|c|}{ Medically Treated Groups } \\
\hline \multicolumn{2}{|c|}{ Moderate number (\%) } & $8(26.8 \%)$ & $7(35 \%)$ \\
\hline \multicolumn{2}{|c|}{ Sever number (\%) } & $20(66.6 \%)$ & $11(55 \%)$ \\
\hline \multicolumn{2}{|c|}{ Critical number (\%) } & $2(6.6 \%)$ & $2(10 \%)$ \\
\hline
\end{tabular}

Table 2. Medical history, MRS and NIHSS at presentation.

\begin{tabular}{|c|c|c|c|c|}
\hline & CAS & $\begin{array}{c}\text { Medical } \\
\text { Treatment }\end{array}$ & $\begin{array}{c}\text { Test of } \\
\text { Significance }\end{array}$ \\
\hline \multicolumn{4}{|c|}{ Medical History } & \\
\hline \multicolumn{2}{|c|}{ Diabetis mellitus } & $21(70 \%)$ & $14(70 \%)$ & \multirow{8}{*}{$P>0.05$} \\
\hline \multicolumn{2}{|c|}{ Hypertension } & 19(63.3\%) & $12(60 \%)$ & \\
\hline \multicolumn{2}{|c|}{$\begin{array}{l}\text { Coronary artery } \\
\text { disease } 17(56.6 \%)\end{array}$} & $11(55 \%)$ & 68.75 & \\
\hline \multicolumn{2}{|l|}{ AF } & $9(30 \%)$ & $6(30 \%)$ & \\
\hline \multicolumn{2}{|c|}{ Dyslipedimia } & $22(73.3 \%)$ & $14(70 \%)$ & \\
\hline \multicolumn{2}{|l|}{ Smoking } & $13(43.3 \%)$ & $8(40 \%)$ & \\
\hline \multicolumn{2}{|c|}{$\begin{array}{l}\text { Peripheral vascular } \\
\text { disease }\end{array}$} & $4(13.3 \%)$ & $4(20 \%)$ & \\
\hline \multicolumn{2}{|c|}{ Previous stroke } & $5(16.6 \%)$ & $3(15 \%)$ & \\
\hline \multicolumn{5}{|l|}{ MRS } \\
\hline \multicolumn{2}{|l|}{0} & $8(26.6 \%)$ & $4(20 \%)$ & \multirow{2}{*}{$P<0.05$} \\
\hline \multicolumn{2}{|l|}{$1-2$} & $22(73.4 \%)$ & $16(80 \%)$ & \\
\hline \multicolumn{5}{|l|}{ NIHSS } \\
\hline Normal & 0 & $8(26.7 \%)$ & $4(20 \%)$ & \multirow{5}{*}{$P>0.05$} \\
\hline MILD & $1-5$ & $7(23.3 \%)$ & $7(35 \%)$ & \\
\hline Moderate & $6-15$ & $15(50 \%)$ & $9(45 \%)$ & \\
\hline $\begin{array}{l}\text { Moderate } \\
\text { to Sever }\end{array}$ & $16-25$ & $0(0 \%)$ & $0(0 \%)$ & \\
\hline Sever & $26-42$ & $0(0 \%)$ & $0(0 \%)$ & \\
\hline
\end{tabular}

Table 3. Outcomes after 6 months.

\begin{tabular}{|c|c|c|c|c|}
\hline & & CAS & $\begin{array}{l}\text { Medical } \\
\text { Treatment }\end{array}$ & $\begin{array}{c}\text { Test of } \\
\text { Significance }\end{array}$ \\
\hline TIA & & $4(13.4 \%)$ & $6(30 \%)$ & \\
\hline Stroke & & $1(3.3 \%)$ & $6(30 \%)$ & \\
\hline Death & & $1(3.3 \%)$ & $2(10 \%)$ & $P<0.01$ \\
\hline No New Ev & ent & $24(80 \%)$ & $6(30 \%)$ & \\
\hline Total & & & 30 & 20 \\
\hline MRS & & & & \\
\hline 0 & & $8(26.6 \%)$ & $4(20 \%)$ & \\
\hline $1-2$ & & $21(73.4 \%)$ & $10(50 \%)$ & \\
\hline 3 & & $0(0 \%)$ & $2(10 \%)$ & \\
\hline 4 & & $0(0 \%)$ & $3(15 \%)$ & \\
\hline 5 & & $0(0 \%)$ & $1(5 \%)$ & \\
\hline 6 & & $1(3.3 \%)$ & $2(10 \%)$ & \\
\hline NIHSS & & & & \\
\hline Normal & 0 & $8(26.7 \%)$ & $3(15 \%)$ & \\
\hline MILD & $1-5$ & $6(20 \%)$ & $5(25 \%)$ & \\
\hline Moderate & $6-15$ & $15(50 \%)$ & $10(50 \%)$ & $P>0.05$ \\
\hline $\begin{array}{l}\text { Moderate } \\
\text { to Sever }\end{array}$ & $16-25$ & $0(0 \%)$ & $0(0 \%)$ & \\
\hline Sever & $26-42$ & $1(3.3 \%)$ & $2(10 \%)$ & \\
\hline
\end{tabular}

\section{Outcome and correlative analysis}

After 6 months 4 (13.4\%) patients in CAS group developed TIA, 1 (3.3\%) patient developed stroke which was after procedure and 1 (3.3\%) patient die due to myocardial infarction while in medically treated group 6 (30\%) patients developed TIA, 6 (30\%) patients developed stroke and 2 (10\%) patients died one of them due to large stroke and the other due to myocardial infarction. There was high significant difference be-tween CAS and medically treated group after 6 months $(p<0.01)$. According to disability as regard MRS after 6 months in each group, In CAS group 8 (26.7\%) patients had MRS 0.21 (70\%) patients had MRS 1-2 and one (3.3\%) patient had MRS 6, while in medically treated group 2 (10\%) patients had MRS 0.10 (50\%) patients had 
MRS 1-2, 2 (10\%) patients and MRS 3, 3 (15\%) patients had MRS 4, one (5\%) patient had MRS 5 and 2 (10) patients had MRS 6. with statically difference between CAS and Medically treated group $(p<0.05)$.As regard NIHSS after 6 months, 8 (26.7\%) of patients in CAS group were normal (NIHSS was $0), 6(20 \%)$ of patients had mild stroke (NIHSS 1-5),15 (50\%) patients had moderate stroke, no patient had moderate to sever and one patient (3.3\%) had sever stroke, while in medically treated group 3 (15\%) patients were normal, 5 (25\%) patients had mild stroke. 10 (50\%) patients had moderate stroke, no patient had moderate to sever and 2 (10\%) had sever stroke with no statically difference between CAS and medically treated group ( $p>0.05$ ).

\section{Discussion}

Atherosclerotic disease of the carotid artery is responsible for 20\%-30\% of all strokes [7] and significant clinically relevant stenosis $>50 \%$ was detected in $(2.5 \%)$ of the atherosclerotic symptomatic subjects [8].

Patient selection to determine the most appropriate means of carotid stenosis management is a complex one and decision regarding the optimal mode of treatment must be determined on an individual patient by patient basis. [9].

The aim of this study is to assess the value and consequences of extracranial carotid artery stenting im-mediately and at short term follow-up versus best medical treatment using clinical assessment and carotid Doppler ultrasonography.

In the present study the mean age of patients is $(66 \pm 7.92$ years) which is younger than most studies as (SAPPHIRE) Stenting and angioplasty with protection in patients at high risk for endarterectomy popula-tion [10], (EVA-3S) Endarterectomy versus stenting in patients with symptomatic severe carotid stenosis [11], (CAVATAS) Carotid and Vertebral Artery Transluminal Angioplasty Study [12], (SPACE) Stent Protected Angioplasty versus Carotid Endar- terectomy [13] and the study done by Naylor et al., 1998 (14) in them the mean age by years was 72.6, $69.7,67,67.9$ and 71 respectively.

The presence of patients with younger age in the current study may be explained by the difference in vascular risk factors between the current study and the other studies, the frequency of diabetes mellitus is more in this study than that in other studies, the frequency of other risk factors as hypercholesterolemia, hypertension, ischemic heart disease and smoking is equal or slightly higher than other studies. This leads to early atherosclerosis and subsequent early occurrence of carotid stenosis in young age [15].

In this study the frequency of carotid stenosis is more common in male than female $54 \%$ versus $46 \%$, this finding is congruent with SAPPHIRE [10] study in which the prevalence of male is more than female (62\%) [16]. De WeERD et al., 2009 [17]found that Prevalence of moderate stenosis increases with age in both men and women, but men at all ages have the higher prevalence estimates.

Sex difference in carotid stenosis is now widely accepted. Sex hormones seem to play a funda-mental protective role in women through widespread actions, affecting endothelial function, lipid homeostasis, and cardiovascular risk factor reduction [18]. Moreover, some authors claim that estrogens might have plaque stabilization properties and effects on inflammatory status [19].

The results of this study showed $0 \%$ restenosis rate after 6 months follow up with $0 \%$ ipsilateral strokes due to restenosis. These results compare well with results of PoweLL et al. (2004) [20] who reported $2.7 \%$ restenosis rate with $0 \%$ stroke after 6 months follow-up. CeRnETTI et al (2003) [21] reported $3.9 \%$ restenosis rate with $0 \%$ stroke. Mudra et al (2003) [22] reported 2.4\% restenosis rate with $0 \%$ stroke. HeNRY et al (2002) [23] reported 0.6\% restenosis rate with $0 \%$ stroke after 6 months follow up. GUPTA et al (2000) [24] reported 1.9\% restenosis rate with $0 \%$ stroke after 18 months follow up. Gross 
et al (1999) [25] reported 3.7\% restenosis rate with $0 \%$ stroke. Also the results of the largest multicenter survey to date by WHOLEY et al (2003) [26] included over 11,243 patients reported $2.7 \%$ restenosis rates after 12 months, 2.6\% after 24 months and $2.4 \%$ after 36 months, the rate of neurologic events after stent placement was $1.2 \%, 1.3 \%$, and $1.7 \%$ at 1,2 , and 3 years, respectively. All these studies used the $\geq 50 \%$ restenosis threshold.

Contrary to results of the present study higher restenosis rates were reported by different studies. SCHILLINGER et al (2004) [27] reported 14\% restenosis rate with 2\% stroke. Bowser et al (2003) [28] reported $15.4 \%$ restenosis rate with $0 \%$ stroke. BonaLDI et al (2002) [29] reported 8\% restenosis rate with 0\% stroke. ChaKhtOuRa et al (2001) [30] reported $12.2 \%$ restenosis rate with $0 \%$ stroke. New et al (2001) [31] reported $7.2 \%$ restenosis rate with $0.6 \%$ stroke. Groschel et al (2005) [32] conducted a systematic analysis of all peer-reviewed studies reporting on the rate of restenosis ( $\geq 50 \%$ ) after carotid artery stenting based on duplex ultrasound or angiography that were published between January 1990 and July 2004. They identified 34 studies that reported on a total of 4,185 patients with a follow-up of 3,814 arteries over a median of 13 months (range, 6 to 31 months). The cumulative restenosis rates after 1 and 2 years were $6 \%$ and $7.5 \%$ in those studies, which used a lower restenosis threshold $\geq 50 \%$ to $70 \%$.

This difference can be explained by that all cases included in the current study carotid stenosis due to atherosclerosis while other studies carotid in-stent restenosis occurs mostly in non- atherosclerotic carotid stenosis lesions (radiation induced carotid stenosis and post-endarterectomy restenosis) which have more liability to restenosis.

According to results of the present study and that of previous studies the short-term restenosis rates after CAS is promising, thus there is a need for further research on the long-term durability of CAS procedures which showed a higher restenosis rates.
Finally, there still is the need for identifying specific risk factors for the development of restenosis after CAS. Some studies have identified advanced age [33], female gender [33], hyperglycemia [34], previous treatment with a CEA [35], and increased serum levels of acute-phase reactants [36] as potential risk factors for the development of a restenosis after CAS; however, the definitive role of these factors remains to be elucidated in larger trials. Also, CAS under protection device is associated with better outcome than medical treatment and it appears to be a safe procedure.

\section{Conclusion}

CAS under protection device is associated with better outcome than best medical treatment and it appears to be a safe procedure.

\section{References}

1. The global burden of disease: 2004 update. Geneva, World Health Organization, 2008.

2. Liapis CD, Avgerinos ED, Chatziioannou A: The Aortic Arch: Markers, Imaging, and Procedure Planning for Carotid Intervention, Vascular Disease Management, 2009; Jan/Feb, Volume 6: http://www.vascular disease management.com.

3. Bailes JE, Medary MB. Carotid endarterectomy. In: Winn HR, ed. Youmans Neurological Surgery, $5^{\text {th }}$ Ed. Saunders, Philadelphia; 2004, pp 1621-1649.

4. Saw J, Walsh S: Aortic Arch and Cerebrovascular Anatomy and Angiography. carotid artery stent-ing: The Basics, part 2009; 4, 10:149-169.

5. www.ninds.nih.gov/doctors/NIH Stroke Scale.pdf.

6. Bonita R, Beaglehole R. "Modification of Rankin Scale: Recovery of motor function after stroke."Stroke 1988 Dec; 19(12):14971500 .

7. Timsit SG, Sacco RL, Mohr JP, Foulkes MA, Tatemichi TK, Wolf PA, Price TR, Hier DB: Early clinical differentiation of cerebral infarction from severe atherosclerotic stenosis and cardioembolism. Stroke 1992; 23:486- 491.

8. Foad Abd Allah, Essam Baligh and Magdy Ibrahim: Clinical Relevance of Carotid Atherosclerosis among Egyptians: A 5-Year Retrospective Analysis of 4, 733 Subjects. Neuroepidemiology 2010; 35:275-279 
9. Yadav JS, Wholey MH and Kuntz RE; Protected carotid-artery stenting versus endarterectomy in high-risk patients. N Engl J Med 2004; 351:1493-501.

10. Jacqueline Saw, Davis S. Lee. Indications for carotid artery stenting. IN: Handbook of complex per-cutaneous carotid intervention. New Jersy: Humana Press, 2007; 111-127.

11. Mas JL, Trinquart $L$, Leys $D$, Albucher JF, Rousseau $H$, Viguier $A$, Bossavy JP, Denis B, Piquet P, Garnier P, Viader F, Touzé E, Julia $P$, Giroud M, Krause D, Hosseini H, Becquemin JP, Hinzelin G, Houdart E, Hénon H, Neau JP, Bracard S, Onnient Y, Padovani $\mathrm{R}$,. Endarterectomy Versus Angioplasty in Patients with Symptomatic Severe Carotid Stenosis (EVA-3S) trial: results up to 4 years from a randomised, multicentre trial. Lancet Neurol 2008; 7:885-92.

12. Brahmanandam S, Ding EL, Michael $S$, : Clinical results of carotid artery stenting compared with carotid endarterectomy J Vasc Surg 2008:47:343-9.

13. Ringleb PA, Allenberg J, Brückmann $H$, Eckstein $H H$, Fraedrich G, Hartmann M, Hennerici M, Jansen O, Klein G, Kunze A, Marx P, Niederkorn K, Schmiedt W, Solymosi L, Stingele R, Zeumer H, Hacke W. 30 day results from the SPACE trial of stent-protected angioplasty versus carotid endarterectomy in symptomatic patients: a randomised non-inferiority trial. Lancet 2006; 368:1239-47.

14. Naylor AR, Bolia A, Abbott RJ,: Randomized study of carotid angioplasty and stenting versus carotid endarterectomy: a stopped trial. J Vasc Surg 1998; 28:326 34

15. Arvisalo MJ, Raitakari M, Toikka JO, Endothelial dysfunction and increasedarterial intima-media thickness in children with type 1 diabetes. Circulation2004; 109: 1750-1755.

16. Massop D, Dave R, Metzger C, Bachinsky W, Solis M, Shah R, Schultz G, Schreiber T, Ashchi M, Hibbard R; SAPPHIRE Worldwide Investigators. Stenting and angioplasty with protection in patients at high-risk for endarterectomy: SAPPHIRE Worldwide Registry first 2, 001 pa-tients. Catheter Cardiovasc Interv. 2009 Feb 1; 73(2):129-36.

17. dWeerd M1, Greving JP, de Jong AW, Buskens E, Bots ML: Prevalence of asymptomatic carotid artery stenosis according to age and sex: systematic review and metaregression analysis. Stroke. 2009 Apr; 40(4):1105-13.

18. Agrinier N., M. Cournot, J. Dallongeville, D. Arveiler, P. Ducimetière, J.B. Ruidavets, et al. Meno-pause and modifiable coronary heart disease risk factors: a population based study Maturitas, 65 (2010), pp. 237-243.

19. Iemolo F., A. Martiniuk, D.A. Steinman, J.D. Spence Sex differences in carotid plaque and stenosis Stroke, 35 (2004), pp. 477-481.

20. Powell RJ, Schermerhorn M, Nolan B: Early results of carotid stent placement for treatment of extracranial carotid bifurcation occlusive disease. J Vasc Surg 2004. 39:1193-1199.
21. Cernetti $C$, Reimers $B$, Picciolo $A$,: Carotid artery stenting with cerebral protection in 100 con- secutive patients: immediate and two-year follow-up results. Ital Heart J 2003:4:695,

22. Mudra H, Ziegler $M$, Haufe MC, Hug M, Knape A, Meurer A, Pitzl H, Büchele W, Spes C. Percutaneous carotid angioplasty with stent implantation and protection device against embolism-a prospective study of 100 consecutive cases. Dtsch Med Wochenschr. 2003 Apr 11; 128(15):790-6. German.

23. Henry M, Henry I, Klonaris $C_{\text {, }}$ : Benefits of cerebral protection during carotid stenting with the Percu-Surge Guard Wire system: midterm results. J Endovasc Ther2002; 9:1-13.

24. Gupta A, Bhatia A, Ahuja A, Shalev Y, Bajwa T. Carotid stenting in patients older than 65 years with inoperable carotid artery disease: a single-center experience. Catheter Cardiovasc Interv. 2000 May; 50(1):1-8; discussion 9.

25. Gross CM, Krämer J, Uhlich F, Tamaschke C, Vogel P, Friedrich I, Dietz R, Waigand J. Treatment of carotid artery stenosis by elective stent placement instead of carotid endarterectomy in patients with severe coronary artery disease. Thromb Haemost. 1999 Sep; 82 Suppl 1:176-80.

26. Wholey $\mathrm{MH}$, Al-Mubarek $\mathrm{N}$ : Updated review of the global carotid artery stent registry. Catheter Cardiovasc Interv; 2003 60:259-266

27. Schillinger $M$, Exner $M$, Sabeti $S$, Amighi J, Wagner $O$, Ahmadi $\mathrm{R}$, Minar E. Excessive carotid in-stent neointimal formation predicts late cardiovascular events. J Endovasc Ther. 2004 Jun; 11(3):229-39.

28. Bowser AN, Bandyk DF, Evans A, Novotney M, Leo F, Back MR, Johnson BL, Shames ML. Out-come of carotid stent-assisted angioplasty versus open surgical repair of recurrent carotid stenosis.J Vasc Surg. 2003 Sep; 38(3):432-8.

29. Bonaldi G. Angioplasty and stenting of the cervical carotid bifurcation: report of a 4-year se-ries. Neuroradiology. 2002 Feb; 44(2):164-74.

30. Chakhtoura EY, Hobson RW 2nd, Goldstein J, Simonian GT, Lal BK, Haser PB, Silva MB Jr, Padberg FT Jr, Pappas PJ, Jamil Z. In-stent restenosis after carotid angioplasty-stenting: incidence and management. J Vasc Surg. 2001 Feb; 33(2):220-5; discussion 225-6.

31. New G, Roubin GS, lyer SS, : mmediate and late clinical outcomes of carotid artery stenting in patients with symptomatic and asymptomatic carotid artery stenosis: a 5-year prospective analysis. Circulation2001; 103(4):532-7.

32. Gröschel K, Riecker A, Schulz JB, Ernemann U, Kastrup A. Systematic review of early recurrent stenosis after carotid angioplasty and stenting. Stroke. 2005 Feb; 36(2):367-73. 
33. Khan MA, Liu MW, Chio FL, Roubin GS, lyer SS, Vitek JJ. Predictors of restenosis after successful carotid artery stenting. Am J Cardiol. 2003 Oct 1; 92(7):895-7.

34. Willfort-Ehringer A, Ahmadi R, Gessl A, Gschwandtner ME, Haumer A, Lang W, Minar E, Zehetmayer S, Ehringer $\mathrm{H}$. Neointimal proliferation within carotid stents is more pronounced in diabetic patients with initial poor glycaemic state. Diabetologia. 2004 Mar; 47(3):400-6.

35. Setacci C, Pula G, Baldi I, de Donato G, Setacci F, Cappelli A, Pieraccini M, Cremonesi A, Castriota F, Neri E. Determinants of in-stent restenosis after carotid angioplasty: a case-control study. J Endovasc Ther. 2003 Dec; 10(6):1031-8.

36. Schillinger $M$, Exner $M$, Mlekusch $W$, Rumpold $H$, Ahmadi $R$, Sabeti S, Lang W, Wagner O, Minar E. Acute-phase response after stent implantation in the carotid artery: association with 6-month in-stent restenosis. Radiology. 2003 May; 227(2):51621.

37. Restenosis after carotid angioplasty: a case-control study. J Endovasc Ther. Dec; 10(6):1031-8.

38. Schillinger $M$, Exner $M$, Mlekusch $W$, Rumpold $H$, Ahmadi R, Sabeti S, Lang W, Wagner O, Minar E(2003). Acutephase response after stent implantation in the carotid artery: association with 6-month in-stent restenosis. Radiology. May; 227(2):516-21

Publish in International Archives of Medicine

International Archives of Medicine is an open access journal publishing articles encompassing all aspects of medical science and clinical practice. IAM is considered a megajournal with independent sections on all areas of medicine. IAM is a really international journal with authors and board members from all around the world. The journal is widely indexed and classified Q1 in category Medicine. 